\title{
Risk of travel-related cases of Zika virus infection is predicted by transmission intensity in outbreak-affected countries
}

\author{
Nicholas H. Ogden ${ }^{1 *}$, Aamir Fazil ${ }^{2}$, David Safronetz ${ }^{3}$, Michael A. Drebot ${ }^{3}$, Justine Wallace ${ }^{2}$, Erin E. Rees ${ }^{1}$, \\ Kristina Decock ${ }^{3}$ and Victoria $\mathrm{Ng}^{2}$
}

\begin{abstract}
Background: Zika virus (ZIKV) infection is emerging globally, currently causing outbreaks in the Caribbean, and Central and South America, and putting travellers to affected countries at risk. Model-based estimates for the basic reproduction number $\left(R_{0}\right)$ of ZIKV in affected Caribbean and Central and South American countries, obtained from 2015 to 2016 human case surveillance data, were compared by logistic regression and Receiver-Operating Characteristic (ROC), with the prevalence of ZIKV-positive test results in Canadians who travelled to them.

Results: Estimates of $R_{0}$ for each country were a good predictor of the ZIKV test result (ROC area under the curve $=0.83$ ) and the odds of testing positive was 11 -fold greater for travellers visiting countries with estimated $R_{0} \geq 2.76$, compared to those visiting countries with $R_{0}<2.76$.

Conclusions: Risk to travellers varies widely amongst countries affected by ZIKV outbreaks. Estimates of $R_{0}$ from surveillance data can assist in assessing levels of risk for travellers and may help improve travel advice. They may also allow better prediction of spread of ZIKV from affected countries by travellers.
\end{abstract}

Keywords: Zika virus, Travellers, Risk, Basic reproduction number

\section{Background}

Zika virus (ZIKV) infection is a globally emerging infectious disease that is, at the time of writing, particularly affecting countries in the Caribbean, and Central and South America [1]. Outcomes of ZIKV infection are mild in most cases but in recent outbreaks more severe outcomes, including Guillain-Barré syndrome (GBS) and foetal central nervous system developmental abnormalities (particularly microcephaly), are now recognised [2]. It is thought that ZIKV is primarily transmitted in tropical and subtropical regions by the mosquitoes Aedes aegypti and Ae. albopictus [3, 4], but sexual transmission also occurs in humans [5-8]. However, to date epidemic/endemic transmission of ZIKV has been limited to tropical and subtropical regions (according to data in [4]). This suggests that sexual transmission, or temperate zone mosquito species,

\footnotetext{
* Correspondence: nicholas.ogden@phac-aspc.gc.ca

${ }^{1}$ National Microbiology Laboratory, Public Health Agency of Canada, rue

Sicotte, Saint-Hyacinthe, Québec, Canada

Full list of author information is available at the end of the article
}

are not capable of maintaining ongoing transmission on their own in the absence of tropical/subtropical Aedes spp. vectors [4, 9] and/or a climate warm enough for ZIKV transmission by these species $[4,10]$.

To manage risks for residents of ZIKV-free countries there are two key questions: (i) How does risk for travelling citizens vary from one affected country to another? This is a function of environmental factors (e.g. climate, habitat, altitude) and socioeconomic factors (e.g. population density, the built environment and the capacity for countries to control infection) that determine the location-specific efficiency of virus transmission cycles and thus the abundance of human-biting infective vectors [11-13]. (ii) From which affected countries are returning travellers most likely to come with ZIKV viraemia and possibly capable of seeding endemic transmission? This also depends on the abundance of human-biting infective vectors, but also on the total numbers of travellers and the proportions that use air travel, the speed of which allows infected individuals to travel long distances while still 
viraemic [14]. The proportions of travellers infected may simply correlate with the force of infection in affected countries. However, many travellers may go to holiday resorts or other locations where the risk of infection is dramatically different from that of the resident populations.

The intrinsic location-specific efficiency of mosquitoborne virus transmission cycles determines the level of risk of Zika virus infection to which travellers are exposed, and during the initial phase of an outbreak this risk of infection is positively associated with the basic reproduction number $\left(R_{0}\right)$ of Zika virus in the affected country. $R_{O}$ is the number of new cases of disease in humans produced by one case in a naïve population under the conditions of the particular location under study, and is the gold-standard metric of the capacity of an infectious agent to propagate [15].

In this study we assess the relationship between the proportions of Canadian travellers that test positive for ZIKV after travelling to countries where ZIKV is or has recently been epidemic, and estimates for $R_{0}$ in those countries obtained from human case surveillance data. We find evidence that these are related, suggesting that estimation of transmission efficiency in affected countries may be used to nuance assessments of risk for travellers, and allow more precise estimates of the rates of introduction and spread of ZIKV by ZIKV-viraemic travellers.

\section{Methods}

\section{Zika surveillance data}

Data for 39 countries and territories of the Caribbean, and Central and South America with confirmed autochthonous transmission of ZIKV were obtained from the Pan American Health Organization [16]. Data extracted on June 16, 2016 contained 377,525 ZIKV cases (364,030 suspected and 13,495 confirmed cases) reported between August 15, 2015 and June 11, 2016. Case counts were reported by epidemiological week with a date corresponding to the first day of that week. PAHO provides recommendations for case definitions of confirmed and suspected cases [17]; however, case definitions vary amongst countries and these are detailed in Additional file 1. For this study, confirmed and suspected cases were combined for each country due to the varying case definitions and degree to which confirmed and suspected cases are reported.

\section{Estimation of the basic reproduction number $\left(R_{0}\right)$}

The Incidence Decay and Exponential Adjustment (IDEA) model was used to estimate $R_{0}$ for each ZIKV affected country. The IDEA model is a one equation, mathematical model that can be used to describe epidemic dynamics when only basic epidemiological information is available [18]. The basis of the IDEA model is that in the absence of intervention or population immunity, the number of cases will grow exponentially with each serial interval $(t$; the time it takes for infection in one person to give rise to infection in another person via transmission by a mosquito) by a factor that is $R_{0}$. In reality, epidemics decay within a timeframe due to processes such as increases in population immunity and/or control efforts of one form or another. The IDEA model accounts for this decay by estimating a "control factor", $d$ which represents all dynamic processes that slow epidemic growth (e.g. public health interventions, declining vector abundance, and increasing herd immunity). The IDEA model form is:

$$
I_{t}=\left(\left(R_{0} /(1+d)^{t}\right)^{t}\right.
$$

where $I_{t}$ is the number of new cases in a serial interval $t$, $R_{O}$ is the basic reproduction number, and $d$ is the control factor [18].

Using this equation, estimates for $R_{O}$ and $d$ were calculated from the changes in case counts observed over successive serial intervals in the ZIKV surveillance data during the epidemic in each affected country. The optimization tool, Solver, in Excel 2010 (Microsoft Corporation, Redmond, WA, US) was used for these estimations. The sum of least squares approach was used to estimate the best fit for $R_{O}$ and $d$ by minimizing the sum of the squared deviations between the observed case counts and the predicted case counts estimated by the model.

For these calculations, time zero of the epidemic in each country was assumed to be the date of the first reported confirmed or suspected ZIKV case. However, in 19 countries multiple cases were reported in the first week of reporting. For these countries a burn-in period was employed, which was the number of weeks prior to the first week of reporting that the first case likely occurred. This number of weeks was simply calculated as the number of times the case counts in the first week of reporting could be divided by two before a case count of one was reached.

The IDEA model requires data input in the time scale of the serial interval $(t)$, so PAHO case data were transformed from weekly case counts to corresponding serial intervals. We selected a serial interval of 16 days based on best estimates of 15 to 16 days with a possible range of 10 to 23 days [19]. To rescale weekly PAHO data into a 16-day serial interval, the PAHO data for each country was linearly interpolated between weeks to obtain estimates of daily case counts using Stata/IC for Windows version 14.1 (College Station, TX, US). Then weekly case count data were matched to each 16-day serial interval (or other serial intervals for sensitivity analysis).

\section{Testing of travellers}

All ZIKV test data used in this study were obtained by testing at the National Microbiology Laboratory (NML), Public Health Agency of Canada. The diagnostic algorithms for 
ZIKV testing in Canadians followed guidelines developed by the Committee to Advise on Tropical Medicine and Travel [20] and mostly agree with recommendations of the United States Centers for Disease Control and Prevention (CDC, [21]) and the World Health Organization [22]. Testing for ZIKV was recommend for: (i) travellers returning to Canada from areas with known or highly suspected ZIKV transmission and who experienced symptoms consistent with ZIKV infection; (ii) asymptomatic pregnant women with travel history to affected regions; and (iii) those having recent sexual contact with a partner who was confirmed to be infected with ZIKV. As the latter type of exposure would not be associated with travel, data on these tests were not included in this study.

ZIKV testing was conducted using diagnostic assays developed and validated by CDC [23]. Acute sera collected within 10-14 days post-onset from symptomatic individuals were first tested for the presence of virus by RT-PCR [23] with samples considered positive if both the gene targets in the PCR were positive. If negative, sera were tested by an IgM-antigen capture enzyme-linked immunosorbent assay (MAC-ELISA) and confirmed by plaque reduction neutralization test (PRNT) [23]. The PRNT assay was conducted in parallel with a dengue virus PRNT assay and only samples that yielded a 4-fold or higher titer for ZIKV were considered positive.

The dataset used in this study comprised all ZIKV tests performed at NML on individuals returning to Canada with a travel history to a ZIKV affected country or territory up to June 21, 2016. The de-nominated dataset included a case ID, the date the test sample was received by NML and information on country/territory or countries/territories to which the case had recently travelled (although precise dates of travel were not available). A total of 5157 unique test samples (of which 111 were positive) with a history of travel were received between May 27, 2015 and June 17, 2016. However after eliminating samples that did not precisely identify countries or territories of travel, travel to potentially Zika-affected countries or territories outside of the Americas and those from travellers who visited multiple Zika-affected countries or territories there were 4533 test results available for the analysis.

\section{Statistical analysis}

The shape of the relationship between the likelihood of a positive ZIKV test result and $R_{O}$ values was investigated by lowess smoothed estimation of the log of the odds ratio for testing positive [24], to see if polynomial forms or categorisation of the explanatory variable were needed for logistic regression analysis [25]. The relationship approximated to a step function so for analysis the data were categorised into two groups with high and low estimated $R_{O}$ values. The performance of $R_{O}$ values as a predictor of the test result was assessed using the receiver operating characteristic (ROC) area under the curve (AUC), and in so doing, values for sensitivity and specificity of different cut-off levels of $R_{0}$ for predicting the test result were generated. ROC analysis provided a basis for selection of a $R_{0}$ cut-off value to categorise the $R_{0}$ values into one low (value $=0)$ and one high (value $=1)$ group for logistic regression analysis. The $R_{O}$ cut-off value chosen was that which gave the highest Youden index (= Specificity/100 + Sensitivity/100 - 1, i.e. giving equal weight to specificity and sensitivity [26]). To quantify the difference in the likelihood of travellers testing positive after visiting countries with high versus low $R_{O}$ values, logistic regression was run using ZIKV test result as the outcome and the dichotomised $R_{O}$ value groups as the explanatory variable. To account for unmeasured sources of variation amongst countries visited, an ID number for the country visited by the traveller was included as a random effect. Analyses were undertaken using Stata/SE for Windows version 14.1 (College Station, TX, US) with the level of significance set at $P<0.05$. Data used in the analyses are available in Additional file 2.

\section{Sensitivity analysis}

The only variable in the IDEA model that can affect estimation of $R_{0}$, and which can be varied by the user, is the serial interval $(t)$. We used a serial interval of 16 days for the main analysis, however this figure is estimated from limited data [19] and will likely vary with different environmental conditions including different seasons, mosquito biting rates and extrinsic incubation period lengths. Therefore a sensitivity analysis was conducted to assess how variations in the value of $t$ may impact the results of the study.

To do this, additional $R_{O}$ estimates for each ZIVKaffected country were estimated using the IDEA model for one lower value for $t$ (10 days) and one higher value (23 days). The performance of the new $R_{O}$ values as predictors of the test result was assessed as above using the ROC AUC. The significance of differences in the AUC values using $R_{O}$ values obtained using the three different values for $t$ were assessed using the roccomp procedure for testing the equality of two or more ROC areas [27] in Stata/SE for Windows version 14.1. A cut-off level for each of the two new $R_{O}$ values, which gave the highest Youden index values, was chosen to dichotomise the $R_{O}$ values into low high groups as described above. Logistic regression models (one for each set of $R_{O}$ values obtained with 10 and 23 day values for $t$ ) were then run using ZIKV test result as the outcome and the dichotomised $R_{O}$ groups as explanatory variable with the ID number for the country visited by the traveller included as a random effect. All analyses were completed using Stata/SE for Windows version 14.1 with the level of significance set at $P<0.05$. 


\section{Results}

\section{Zika surveillance and test result data}

Of the 4533 Canadian traveller test results with information on travel destination to a single country, 104 tested positive and these travellers had visited one of 46 countries or territories in Central and South America. Of these countries or territories there were 39 for which ZIKV surveillance data were available. However data from Belize, Cuba and Grenada were not used because of very low case counts at the time of extraction. Data from Brazil were also not used as they suggested that surveillance began close to the peak of the epidemic and back-interpolation to identify the approximate date of the index case was considered unreliable. Furthermore, surveillance for non-microcephaly cases ceased in early 2016 [28]. Data from Aruba, Paraguay and Peru were not used because the ZIKV case data were sparse having very few (2-3) weeks of reported cases that produced very high $(\geq 9)$ and likely spurious $R_{O}$ values [18]. Data from Puerto Rico were not used because case numbers reported in the second and subsequent weeks of reporting (mean 428 per week) were stable and an order of magnitude lower than the number of cases reported in the first week (2705). These data also resulted in a very high estimated $R_{O}$ value, which we considered likely spurious due to some anomaly in the reporting of cases at the time of data extraction. Consequently, for analysis there were data from 24 countries for which estimates of $R_{0}$ could be obtained, and for which there were ZIKV test result data for Canadian travellers. The latter comprised 3551 test results, of which 92 (2.59\%, exact 95\% confidence interval $[95 \% \mathrm{CI}]=2.09-3.17 \%)$ were positive. The prevalence of positive test results amongst countries varied from 0 to $33.3 \%$ (Fig. 1).

\section{Estimation of $R_{0}$}

Case numbers predicted by the parameter estimates of the IDEA model were in most cases consistent with observed case numbers (Fig. 2). Estimates of $R_{O}$ values obtained for the 24 countries ranged from approaching zero to 8.31 (Fig. 1). The prevalence of positive ZIKV test results varied non-linearly with $R_{O}$ estimates for the countries (Fig. 3).

\section{Receiver operating characteristic analysis}

The ROC AUC value for estimates of $R_{O}$ as predictors of the ZIKV test result was good (AUC $=0.83$, standard error $=0.02,95 \% \mathrm{CI}=0.79-0.87)$ according to accepted criteria [26]. A cut-off value of $\geq 2.76$ for $R_{O}$ was chosen to dichotomise the ZIKV test data, which gave the greatest combined specificity and sensitivity (73.6 and $84.6 \%$, respectively).

\section{Logistic regression analysis}

In logistic regression with country ID included as a random effect, travellers to countries with an estimated $R_{0} \geq 2.76$ were 11 times more likely to test positive than travellers to countries with an estimated $R_{O}<2.76$ (odds ratio $=11.13$; 95\% CI = 3.14-39.25; Wald $Z=3.73, P<0.001$ ).

The proportions of travellers testing positive after travelling to Zika-affected countries with an estimated $R_{O} \geq 2.76$ and $<2.76$ were $11.2 \%(67 / 596)$ and $0.85 \%(25 /$ 2955), respectively.

\section{Sensitivity analysis}

The $R_{O}$ values obtained with 10 and 23 day values for $t$ were respectively lower and higher than the values obtained using $t=16$ days in most cases (Fig. 4). However, for Saint Lucia and Curacao, $R_{O}$ values obtained with 10 and/or 23 day values for $t$ could not be obtained due to

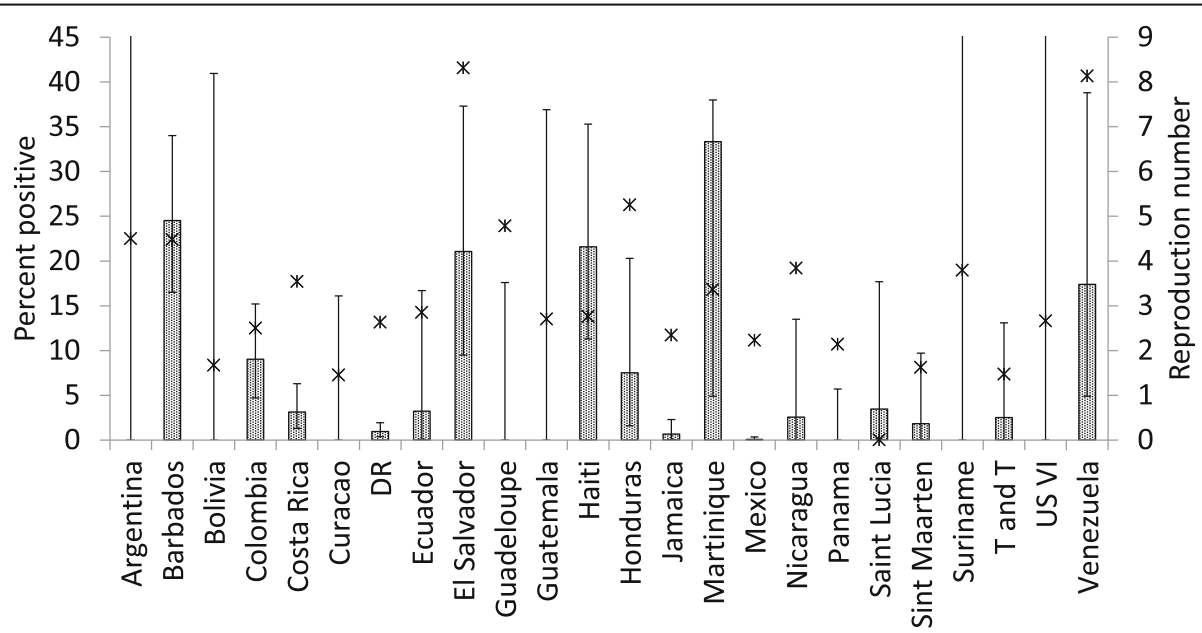

Fig. 1 The prevalence (as a \%) of ZIKV-positive test results (with exact 95\% confidence intervals) in travellers visiting the ZIKV-affected countries on the x-axis. Stars indicate the basic reproduction number $\left(R_{0}\right)$ estimates for each country. Abbreviations: DR, Dominican Republic; T and T, Trinidad and Tobago; US VI, US Virgin Islands 

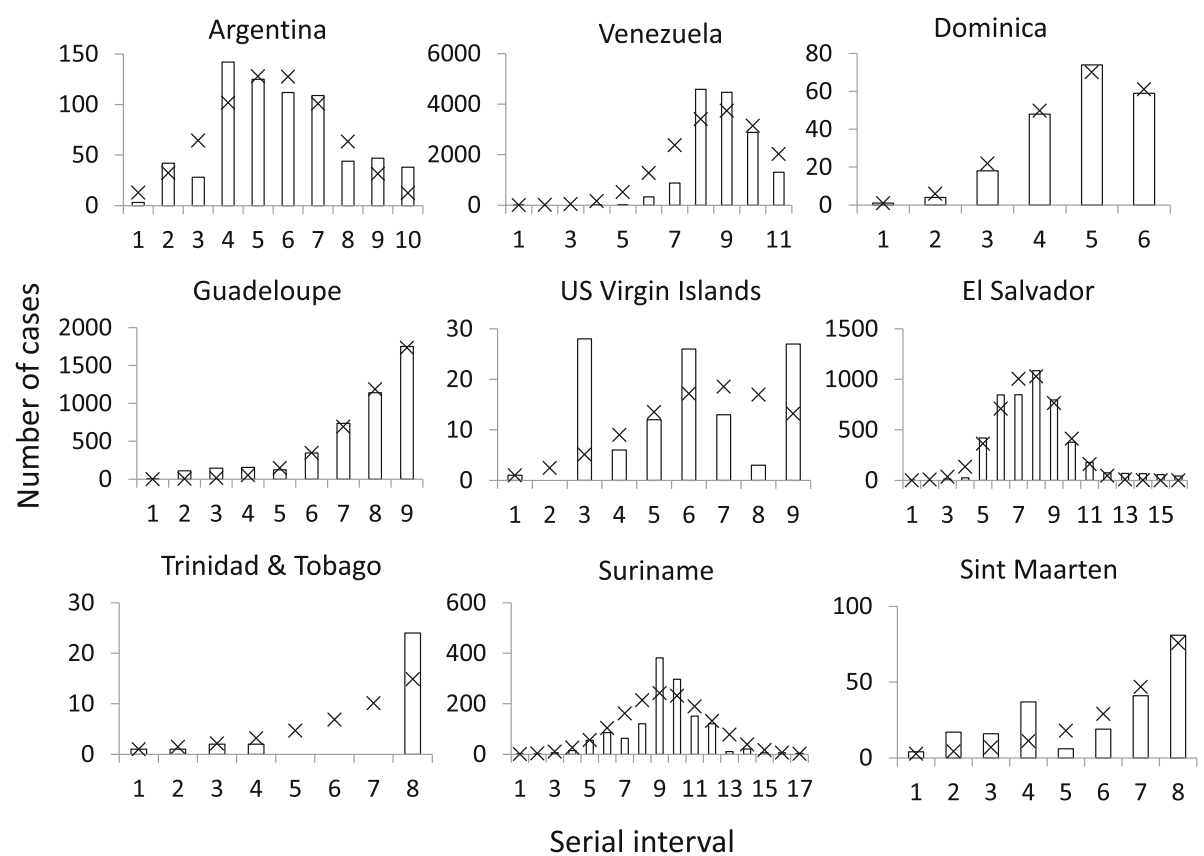

Fig. 2 Example surveillance data from ZIKV-affected countries. The bars show the reported numbers of cases (suspected and confirmed cases combined) by 16 day serial interval period. The crosses show the predicted number of cases using the parameters obtained by the IDEA model [18]

the IDEA model not converging and data from these countries were not used in analyses.

ROC AUC values for the remaining data were the same when $t=16$ days and $t=23$ days but slightly lower when $t=10$ days (Table 1 ). However there was no significant difference between these AUC values $\left(\chi^{2}=1.06\right.$, $P>0.1)$. The optimal cut-off values for dichotomising the $R_{O}$ values were $\geq 1.93$ when $R_{O}$ values were obtained with $t=10$ days and $\geq 3.30$ when $R_{O}$ values were obtained with $t=23$ days. When using these cut-off values the proportions of positive test results in high and low $R_{O}$ groups were the same when $t=23$ days, but different when $t=10$ days (Table 2), which was reflected in the results of logistic regression (Table 3). When $t$ was 23 days the countries falling in the high and low risk groups were the same as when $t$ was 16 days. However when $t$ was 10 days, Colombia, the Dominican Republic and Guatemala were classified as belonging to the high risk group, while they were classified in the low risk group when using $t$ set at 16 and 23 days.

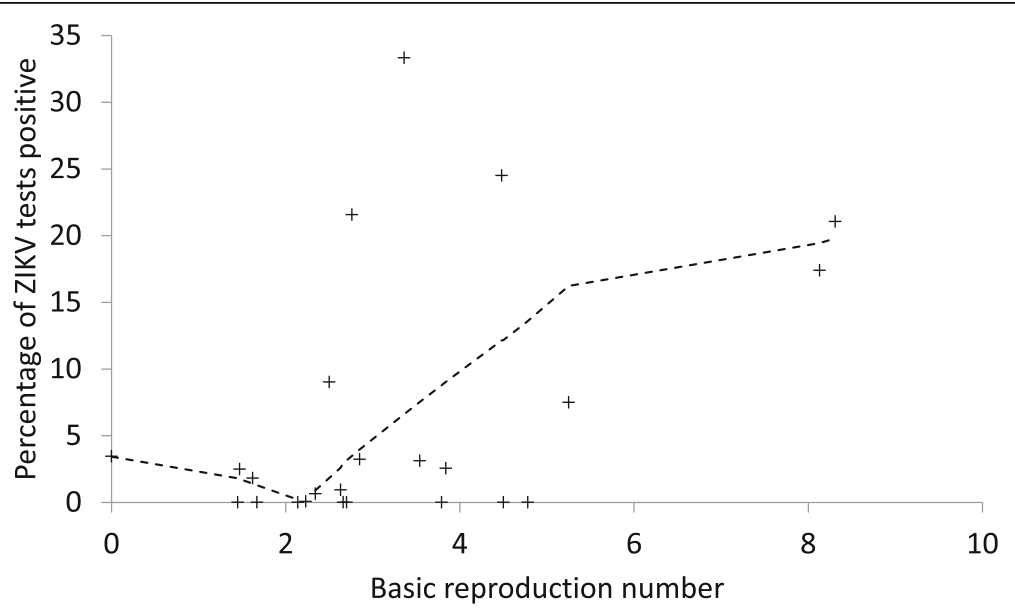

Fig. 3 The relationship of estimates of $R_{0}$ for countries in Central and South America and the Caribbean, to the prevalence of positive ZIKV test results for travellers to those countries. Crosses indicate prevalence values in travellers to an individual country and the dashed line is lowess smoothed estimates of prevalence. The identified cut-off $R_{0}$ value that dichotomised countries into high-risk and low-risk for travellers was 2.76 , and there were 12 countries in each of these groups 


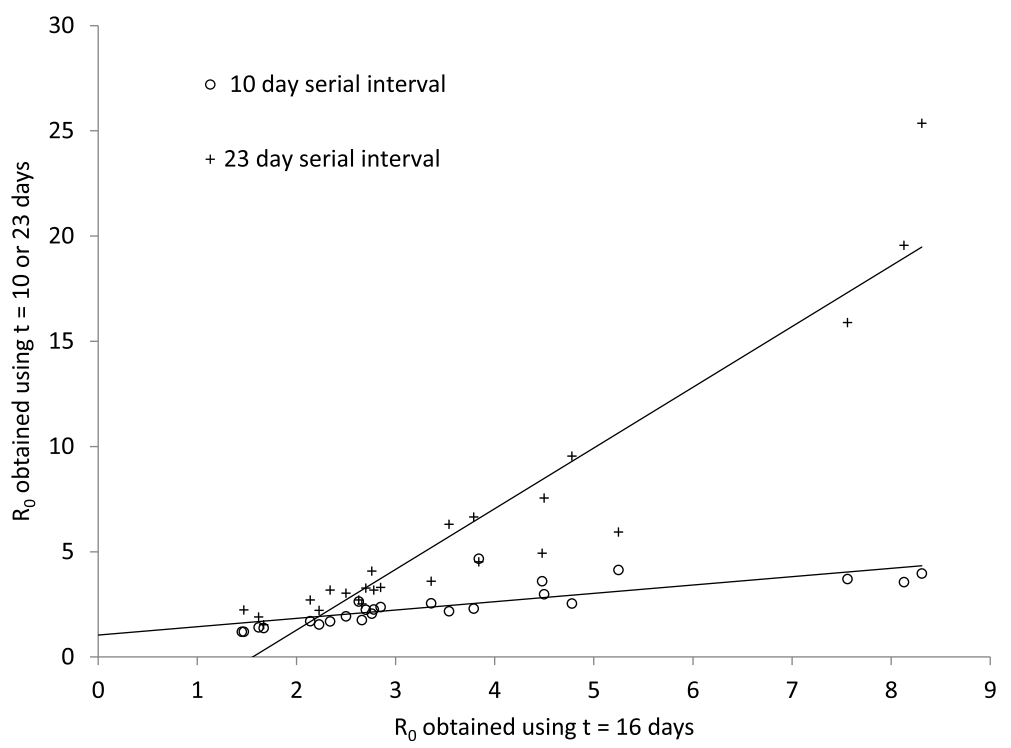

Fig. 4 The relationship between $R_{0}$ estimated using $t=10$ (circles) or $t=23$ days (crosses), and $R_{0}$ estimated using $t=16$ days

\section{Discussion}

Estimates of $R_{O}$ for ZIKV in outbreak-affected countries correlated with the proportions of travellers acquiring ZIKV. Therefore risk to travellers varies with the force of transmission cycles in the countries they are visiting, which suggests that travellers are not a group that is particularly highly protected from infection in affected countries by virtue of their traveller status. This raises the possibility that different levels of ZIKV infection risk in different countries may be identified and possibly communicated to travellers. The need for such nuanced risk communication will become increasingly important if ZIKV spreads more widely in the world, in which case simply not visiting affected countries will become a decreasingly viable decision for many travellers. Second, this study suggests that estimates of $R_{O}$ (or other analyses of the force of infection) in affected countries could be used to enhance methods used to assess the capacity for ZIKV spread by travellers, which often account for within-source country incidence using simple indices $[14,29]$ or not at all [30]. Also, these estimates could provide useful validation data for models predicting

Table 1 Results of ROC analysis for $R_{0}$ as a predictor of the ZIKV test results, when $R_{0}$ was estimated using $t=10,16$ and 23 days. Note that data from Saint Lucia and Curacao were not available for the sensitivity analysis

\begin{tabular}{lcll}
\hline$t$-value used to estimate $R_{0}$ & ROC AUC & SE & $95 \% \mathrm{Cl}$ \\
\hline 10 days & 0.77 & 1.27 & $0.79-0.87$ \\
16 days & 0.79 & 2.34 & $0.74-0.84$ \\
23 days & 0.79 & 2.34 & $0.74-0.83$ \\
\hline
\end{tabular}

Abbreviations: ROC AUC receiver-operating characteristic area under the curve, $S E$ standard error, $\mathrm{Cl}$ confidence interval importation and spread of ZIKV that are being developed [31]. Such models predict actual numbers of cases rather than the numbers reported in surveillance, which vary amongst countries according to surveillance systems and effort, as well as according to the dynamics of ZIKV transmission. The method we used here obtains an estimate of $R_{O}$ based on the shape of the epidemic curve rather than the reported incidence so it allows comparisons to be made amongst jurisdictions in which surveillance effort may be different.

The relationship between estimated $R_{0}$ for the ZIKVaffected countries and infection prevalence in Canadian travellers was nonlinear and we chose to use a simple $R_{0}$ cut-off point to dichotomise the data for analysis. Why this relationship was a step function is not clear. One possible explanation is background noise within the reported ZIKV case numbers, associated with false positivity and negativity, which may mask the real status of transmission when incidence is low. More research and data from more countries and time points during epidemics are needed to better understand the relationship between $R_{O}$ and incidence in travellers. Nevertheless, the difference in incidence in travellers exposed to countries above and below the identified $R_{O}$ cut-off (2.76) was stark. The likelihood of testing positive was an order of magnitude greater in travellers to countries with $R_{O}$ values at or above the cut-off compared to travellers to countries with $R_{O}$ values below the cut-off. The estimates of $R_{0}$ for each country provided an index of the status of Zika transmission and risk of infection for travellers despite variations amongst countries in surveillance effort and case definition, and the fact that we are estimating $R_{O}$ mostly on the basis of symptomatic cases, when most 
Table 2 The proportions of travellers positive in high and low risk countries determined using cut-off levels for $R_{0}$ when $R_{0}$ was estimated using $t=10,16$ and 23 days. Note that data from Saint Lucia and Curacao were not used to estimate proportions when $R_{0}$ was estimated using $t=10$ and 23 days

\begin{tabular}{lccc}
\hline$t$-value used to estimate $R_{0}$ & $\begin{array}{l}\text { Cut-off for } R_{0} \text { used } \\
\text { to determine high } \\
\text { and low risk countries }\end{array}$ & $\begin{array}{l}\text { Proportion (\%) positive } \\
\text { in 'high risk' group }\end{array}$ & $\begin{array}{l}\text { Proportion (\%) positive } \\
\text { in 'low risk' group }\end{array}$ \\
\hline 10 days & 1.98 & $86 / 1480(5.8)$ & $5 / 2042(0.2)$ \\
16 days & 2.76 & $67 / 596(11.2)$ & $25 / 2955(0.1)$ \\
23 days & 3.30 & $67 / 596(11.2)$ & $24 / 2905(0.1)$ \\
\hline
\end{tabular}

ZIKV infections are asymptomatic [2]. For these reasons, the value of $R_{0}=2.76$ may not be a hard and fast cut-off figure, ready to use for developing risk communications. It reflects the status of data we have to present at the onset of the outbreak, both on Canadian travellers and on surveillance in affected countries, and further study will be needed to confirm its appropriateness for development of sound risk communications.

We were not able to obtain an $R_{O}$ value for Brazil for the study period even though it is well recognised that Brazil suffered a very significant epidemic. The prevalence of ZIKV-positive test results in Canadian travellers ( $2 \%, 4 / 203$ tests) was relatively low and more consistent with Brazil being in the low risk group in our study. This suggests that either Brazil was an outlier in terms of environmental risk for travellers equating with incidence of infection, or that the epidemic was largely over by the time many of the travellers visited Brazil. There is indeed some evidence that the latter was the true. Phylogenybased estimates of the date of importation of ZIKV into Brazil are as early as 2013 [32], while evidence from surveillance for late-pregnancy microcephaly suggests that the epidemic peaked early in 2015 [33].

The $R_{O}$ estimates were sensitive to the value for the serial interval, but identification of high and low risk countries using $R_{O}$ estimates was robust to variations in the serial interval from 16 to 23 days. A serial interval of 10 days gave a qualitatively similar but quantitatively somewhat different classification of the countries. Ten days may, however, be biologically implausible as a mean serial interval, so $R_{O}$ values generated using this interval could be expected to be less well predictive of the risk of traveller infection than when using more plausible 16 or 23 day serial intervals. The serial interval comprises the

Table 3 Parameter estimates from logistic regression models in which the ZIKV test result was the outcome and risk group (based on cut-off levels for $R_{0}$ when $R_{0}$ was estimated using $t=10,16$ and 23 days) was the explanatory variable

\begin{tabular}{lclcl}
\hline$R_{0}$ estimated using & Odds ratio & $95 \% \mathrm{Cl}$ & Wald $z$ & $P$ \\
\hline$t=10$ days & 21.76 & $4.39-108.85$ & 3.77 & $<0.001$ \\
$t=16$ days & 11.13 & $3.12-39.25$ & 3.73 & $<0.001$ \\
$t=23$ days & 11.71 & $3.09-44.70$ & 3.61 & $<0.001$ \\
\hline
\end{tabular}

Abbreviation: $\mathrm{Cl}$ confidence interval intrinsic incubation period in humans (minimally 3 days [19], but more likely 5 days and longer [34]), the extrinsic incubation period in mosquitoes (as short as 5 days experimentally [35] but in nature more likely $\geq 10$ days [36]), the time mosquitoes take to feed twice, and considerations of how the gonotrophic cycle in the mosquitoes affects how frequently they feed [37]. Serial intervals have most frequently been estimated at $\geq 14$ days for related flaviviruses $[38,39]$ so it would perhaps be unsurprising if the serial interval of ZIKV infections was similar.

There are other methods of estimating $R_{0}$ or the effective reproduction number $R$ from surveillance data (e.g. $[40,41]$ and articles reviewed in [12]), but the IDEA model approach was convenient because it provided an estimate of $R_{O}$ while accounting for factors (including control, seasonal declines in vector numbers or herd immunity) that contribute to post-epidemic peak declines in incidence. Furthermore, it obtains estimates of $R_{O}$ that allow comparisons to be made amongst jurisdictions in which surveillance effort is different. However, as time goes on, incidence will fall in affected countries for a range of reasons (e.g. development of herd immunity and control efforts), and ZIKV transmission will likely transition from epidemic to endemic status. Once this occurs, methods other than the IDEA model may be more appropriate for assessing risk to travellers from surveillance data.

\section{Conclusions}

This study demonstrated that risk to travellers in ZIKVaffected countries correlates with estimates of $R_{O}$ for those countries obtained using human case surveillance data. This relationship was non-linear with risk of travellers testing positive being over tenfold greater in countries with an estimated $R_{O}$ equal to or greater than 2.76 . This suggests that estimates of the force of infection in ZIKV-affected countries may be use to nuance risk information for travellers, and help predict rates of spread of ZIKV from those countries.

\section{Additional files}

Additional file 1: ZIKV infection surveillance case definitions. (DOCX $57 \mathrm{~kb}$ ) Additional file 2: Data used in this study. (XLSX 13 kb) 


\section{Abbreviations}

95\% Cl: 95\% confidence interval; AUC: Area under the curve; CDC: United States Centers for Disease Control and Prevention; IDEA: Incidence decay and exponential adjustment model; MAC-ELISA: IgM-antigen capture enzyme-linked immunosorbent assay; NML: National Microbiology Laboratory; PAHO: Pan American Health Organization; PRNT: Plaque reduction neutralization test; $R_{0}$ : The basic reproduction number; ROC: Receiver operating characteristic; RT-PCR: Reverse transcriptase polymerase chain reaction; SE: Standard error; ZIKV: Zika virus

\section{Acknowledgements}

The authors acknowledge the assistance of Dr L. Robbin Lindsay in this study.

\section{Funding}

This study was funded by the Public Health Agency of Canada. This article was reviewed and approved for submission by the funding source.

\section{Availability of data and material}

All data analysed during this study are included in the article and its additional files.

\section{Authors' contributions}

$\mathrm{NHO}, \mathrm{AF}$ and $\mathrm{VN}$ conceived the study and conducted the analysis with contributions from JW and EER. DS and MAD undertook the laboratory analysis. KD and JW obtained and managed the data. All authors read and approved the final version of the manuscript.

\section{Competing interests}

The authors declare that they have no competing interests.

\section{Consent for publication}

Not applicable.

\section{Ethics approval}

Formal ethical review was not sought because, in line with current guidelines [42], the study relied solely on secondary use of anonymous information, and there was no data linkage, recording or dissemination of results that could generate identifiable information.

\section{Author details}

${ }^{1}$ National Microbiology Laboratory, Public Health Agency of Canada, rue Sicotte, Saint-Hyacinthe, Québec, Canada. ${ }^{2}$ National Microbiology Laboratory, Public Health Agency of Canada, Research Lane, Guelph, ON, Canada. ${ }^{3}$ National Microbiology Laboratory, Public Health Agency of Canada, Arlington Rd., Winnipeg, MB, Canada.

Received: 19 October 2016 Accepted: 10 January 2017

\section{Published online: 25 January 2017}

\section{References}

1. World Health Organisation. http://www.who.int/emergencies/zika-virus/ situation-report/28-july-2016/en/. Accessed 10 Jan 2017

2. Petersen LR, Jamieson DJ, Powers AM, Honein MA. Zika virus. N Engl J Med. 2016;374:1552-63.

3. Guerbois M, Fernandez-Salas I, Azar SR, Danis-Lozano R, Alpuche-Aranda CM, Leal G, et al. Outbreak of Zika virus infection, Chiapas State, Mexico, 2015, and first confirmed transmission by Aedes aegypti mosquitoes in the Americas. J Infect Dis. in press 2016.

4. Messina JP, Kraemer MU, Brady OJ, Pigott DM, Shearer FM, Weiss DJ, et al. Mapping global environmental suitability for Zika virus. Elife. 2016;19:5.

5. Foy BD, Kobylinski KC, Chilson Foy JL, Blitvich BJ, Travassos da Rosa A, Haddow AD, et al. Probable non-vector-borne transmission of Zika virus, Colorado, USA. Emerg Infect Dis. 2011;17:880-2.

6. Hills SL, Russell K, Hennessey M, Williams C, Oster AM, Fischer M, et al. Transmission of Zika virus through sexual contact with travelers to areas of ongoing transmission - continental United States, 2016. MMWR Morb Mortal Wkly Rep. 2016;65:215-6

7. Davidson A, Slavinski S, Komoto K, Rakeman J, Weiss D. Suspected female-tomale sexual transmission of Zika virus - New York City. MMWR Morb Mortal Wkly Rep. 2016;65:716-7.
8. Deckard DT, Chung WM, Brooks JT, Smith JC, Woldai S, Hennessey M, et al. Male-to-male sexual transmission of Zika virus - Texas, January 2016. MMWR Morb Mortal Wkly Rep. 2016;65:372-4.

9. Kraemer MU, Sinka ME, Duda KA, Mylne AQ, Shearer FM, Barker CM, et al. The global distribution of the arbovirus vectors Aedes aegypti and Ae. albopictus. Elife. 2015;4:e08347.

10. Ng V, Fazil A, Gachon P, Deuymes G, Radojević M, Mascarenhas M, et al. Environ Health Perspect. 2016; (In press).

11. Kilpatrick AM, Randolph SE. Drivers, dynamics, and control of emerging vector-borne zoonotic diseases. Lancet. 2012;380:946-55.

12. Ogden NH, Radojevic M, Wu X, Duvvuri VR, Leighton PA, Wu J. Estimated effects of projected climate change on the basic reproductive number of the Lyme disease vector Ixodes scapularis. Environ Health Perspect. 2014;122:631-8.

13. Parham PE, Waldock J, Christophides GK, Hemming D, Agusto F, Evans KJ, et al. Climate, environmental and socio-economic change: weighing up the balance in vector-borne disease transmission. Philos Trans R Soc Lond B Biol Sci. 2015;370: doi: 10.1098/rstb.2013.0551.

14. Bogoch II, Brady OJ, Kraemer MU, German M, Creatore MI, Kulkarni MA, et al. Anticipating the international spread of Zika virus from Brazil. Lancet. 2016; 387:335-6.

15. Anderson RM, May RM. Infectious diseases of humans, dynamics and control. Oxford: Oxford University Press; 1991.

16. http://ais.paho.org/phip/viz/ed_zika_epicurve.asp. Accessed 10 Jan 2017.

17. http://www.paho.org/hq/index.php?option=com_content\&view=article\&id= 11117\&ltemid=41532\&lang=en. Accessed 10 Jan 2017

18. Fisman DN, Hauck TS, Tuite AR, Greer AL. An IDEA for short term outbreak projection: nearcasting using the basic reproduction number. PLoS One. 2013;8:e83622.

19. Majumder MS, Cohn E, Fish D, Brownstein JS. Estimating a feasible serial interval range for Zika fever [Submitted]. Bull World Health Organ, Accessed 10 Jan 2017

20. Committee to Advise on Tropical Medicine and Travel (CATMAT). Canadian recommendations on the prevention and treatment of Zika virus: Update. Can Commun Dis Rep. 2016:42:101-11.

21. Oduyebo T, Igbinosa I, Petersen EE, Polen KN, Pillai SK, Ailes EC, et al. Update: Interim guidance for health care providers caring for pregnant women with possible Zika virus exposure - United States, July 2016. MMWR Morb Mortal Wkly Rep. 2016:65:739-44.

22. World Health Organisation. Laboratory testing for Zika virus infection interim guidance 23 March 2016. http://apps.who.int/iris/bitstream/10665/ 204671/1/WHO_ZIKV_LAB_16.1_eng.pdf?ua=1. Accessed 10 Jan 2017.

23. Lanciotti RS, Kosoy OL, Laven JJ, Velez JO, Lambert AJ, Johnson AJ, et al. Genetic and serological properties of Zika virus associated with an epidemic, Yap Island, Microensia, 2007. Emerg Infect Dis. 2008;14:1232-9.

24. Royston P. gr6: Lowess smoothing. Stata Tech Bull. 1991;3:7-9.

25. Dohoo I, Martin E, Stryhn H. Veterinary epidemiologic research. 2nd ed. Charlottetown: AVC Inc; 2003. p. 349-57.

26. Greiner M, Pfeiffer D, Smith RD. Principles and practical application of the receiver-operating characteristic analysis for diagnostic tests. Prev Vet Med. 2000;45:23-41.

27. DeLong ER, DeLong DM, Clarke-Pearson DL. Comparing the areas under two or more correlated receiver operating characteristic curves: A nonparametric approach. Biometrics. 1988:44:837-45.

28. World Health Organisation Zika Situation Report $5^{\text {th }}$ February 2016. http:// www.who.int/emergencies/zika-virus/situation-report/5-february-2016/en/. Accessed 10 Jan 2017

29. Nah K, Mizumoto K, Miyamatsu Y, Yasuda $Y$, Kinoshita R, Nishiura H. Estimating risks of importation and local transmission of Zika virus infection. PeerJ. 2016;4:e1904.

30. Huff A, Allen T, Whiting K, Breit N, Arnold B. FLIRT-ing with Zika: A web application to predict the movement of infected travelers validated against the current Zika virus epidemic. PLoS Curr. 2016;10:8.

31. Zhang Q, Sun K, Chinazzi M, Pastore-Piontti A, Dean NE, Rojas DP, et al. Projected spread of Zika virus in the Americas. 2016. Posted online at http:// biorxiv.org/content/early/2016/07/29/066456. Accessed 10 Jan 2017

32. Faria NR, Azevedo Rdo S, Kraemer MU, Souza R, Cunha MS, Hill SC, et al. Zika virus in the Americas: Early epidemiological and genetic findings. Science. 2016:352:345-9.

33. França GV, Schuler-Faccini L, Oliveira WK, Henriques CM, Carmo EH, Pedi VD, et al. Congenital Zika virus syndrome in Brazil: a case series of the first 1501 livebirths with complete investigation. Lancet. 2016;388:891-7. 
34. Zhang J, Jin X, Zhu Z, Huang L, Liang S, Xu Y, et al. Early detection of Zika virus infection among travellers from areas of ongoing transmission in China. J Travel Med. 2016;23: doi: 10.1093/jtm/taw047.

35. Li MI, Wong PSJ, Ng LC, Tan CH. Oral susceptibility of Singapore Aedes (Stegomyia) aegypti (Linnaeus) to Zika virus. PLoS Negl Trop Dis. 2012;6:e1792.

36. Tjaden NB, Thomas SM, Fischer D, Beierkuhnlein C. Extrinsic incubation period of dengue: knowledge, backlog, and applications of temperature dependence. PLoS Negl Trop Dis. 2013;7:e2207.

37. Cauchemez S, Ledrans M, Poletto C, Quenel P, de Valk H, Colizza V, et al. Local and regional spread of chikungunya fever in the Americas. Euro Surveill. 2014;19:20854.

38. Aldstadt J. An incremental Knox test for the determination of the serial interval between successive cases of an infectious disease. Stochastic Environ Res Risk Assess. 2007;21:487.

39. Aldstadt J, Yoon IK, Tannitisupawong D, Jarman RG, Thomas SJ, Gibbons RV et al. Trop Med Int Health. 2012;17:1076-85.

40. Lipsitch M, Cohen T, Cooper B, Robins JM, Ma S, James L, et al. Transmission dynamics and control of severe acute respiratory syndrome. Science. 2003; 300:1966-70.

41. Tuite AR, Tien J, Eisenberg M, Earn DJ, Ma J, Fisman DN. Cholera epidemic in Haiti, 2010: using a transmission model to explain spatial spread of disease and identify optimal control interventions. Ann Intern Med. 2011; 154:593-601.

42. Tri-Council (Canadian Institutes of Health Research, Natural Sciences and Engineering Research Council of Canada, Social Sciences and Humanities Research Council of Canada). Tri-Council Policy Statement: Ethical conduct for research involving humans. Ottawa: Government of Canada; 2014.

Submit your next manuscript to BioMed Central and we will help you at every step:

- We accept pre-submission inquiries

- Our selector tool helps you to find the most relevant journal

- We provide round the clock customer support

- Convenient online submission

- Thorough peer review

- Inclusion in PubMed and all major indexing services

- Maximum visibility for your research

Submit your manuscript at www biomedcentral.com/submit
() BioMed Central 